\title{
Reduction of the concentration and total amount of keratan sulphate in synovial fluid from patients with osteoarthritis during treatment with piroxicam
}

\author{
G J Carroll, M C Bell, B A Laing, S McCappin, C Blumer, A Leslie
}

\begin{abstract}
To study the effects of piroxicam on cartilage metabolism in vivo, a three phase (placebo/ piroxicam $20 \mathrm{mg} /$ day by mouth/placebo) double blind controlled trial was conducted in patients with osteoarthritis of the knee joint. Twenty one patients were recruited, 19 of whom (11 women, eight men, median age 70 years) completed the treatment schedule. The knee joint under study was aspirated to dryness at four week intervals. Treatment with piroxicam was accompanied by a decrease in the pain score, an improvement in the functional index, and an increased range of movement. Reductions in the concentration (mean (SEM) 120 (6) to $110(8) \mu \mathrm{g} / \mathrm{ml})$ and the total amount $(1.22$ $(0.34)$ to $0.99(0.37) \mathrm{mg})$ of keratan sulphate, but not the effusion volume $(9.4(2.5)$ to 8.3 $(2.6) \mathrm{ml}$ ) were observed during treatment with piroxicam. These findings are consistent with decreased proteoglycan catabolism during treatment with piroxicam. Neither depressed synthesis nor enhanced clearance of degraded proteoglycan fragments can be excluded, however.
\end{abstract}

(Ann Rheum Dis 1992; 51: 850-854)

Osteoarthritis is a common disease which affects at least one in every three people over 35 years of age irrespective of ethnic origin. ' Many of those affected use non-steroidal anti-inflammatory drugs (NSAIDs) for symptomatic relief. ${ }^{1}$ As osteoarthritis is characterised by progressive resorption of the articular cartilage it is pertinent to consider the effects of NSAIDs on cartilage metabolism. The in vitro effects of NSAIDs on cartilage have been studied in isolated chondrocytes, cartilage explants, and in animals with and without induced arthritis. ${ }^{2-6}$ The results have varied, but in several systems negative effects on proteoglycan synthesis have been observed. ${ }^{2-6}$

Piroxicam is a widely used NSAID which has been shown to reduce the incidence of osteoarthritic lesions in genetically susceptible C57 black mice. ${ }^{7}$ In rats and dogs piroxicam does not affect proteoglycan synthesis in vitro. Whether it affects proteoglycan catabolism in animals or humans is still unclear; however, the findings of Verbruggen et al suggest that it may retard the release of proteoglycans from human cartilage matrix. ${ }^{8}$

The purpose of this study was to examine the effect of piroxicam on the release of proteoglycans from articular cartilage in patients with osteoarthritis of the knee joint.
Patients and methods

PATIENT SELECTION

Patients were selected for study if they were aged 18-80, satisfied the American Rheumatism Association criteria for osteoarthritis of the knee joint, ${ }^{9}$ had at least a small effusion in the affected knee, and gave informed consent. Patients who were pregnant, had active peptic ulcer disease, heart, renal, or liver failure, coagulation disorders, a history of allergy to piroxicam or other NSAIDs, and those already receiving piroxicam were excluded.

EXPERIMENTAL DESIGN

A double blind three phase placebo controlled crossover design was used. Before the study all NSAIDs were slowly tapered and stopped altogether one week before starting the drug treatment. Patients were provided with $500 \mathrm{mg}$ paracetamol and instructed to take up to $1 \mathrm{~g}$ at four hourly intervals as needed. Consumption was monitored and recorded at two week intervals. Following baseline measurements patients received a single daily placebo capsule for four weeks, a single capsule containing 20 mg piroxicam for four weeks, and then the placebo capsule again for a further four weeks. Neither the patients nor the metrologist who undertook the clinical assessment were aware of the experimental design. The placebo and piroxicam capsules were indistinguishable.

\section{CLINICAL ASSESSMENT}

Subjects were assessed by a doctor and a metrologist at two week intervals throughout the study. At each visit patients were asked whether the drug had upset them in any way. Particular side effects were not solicited. Pain was scored on a visual analogue scale. The range of movement was measured with an international scale goniometer according to the method of Norkin et al. ${ }^{10} \mathrm{~A}$ functional index was determined by averaging visual analogue responses to questions concerning the degree of difficulty associated with rising from a sitting position, descending and ascending stairs, standing, walking on flat surfaces, getting into and out of a car, and performing light and heavy domestic duties. These questions were selected from the report by Bellamy and Buchanan, who found that disability in these areas ranked highly in patients with osteoarthritis of the hip and knee joints. ${ }^{11}$ At $0,4,8$, and 12 weeks the size of the effusion was determined by aspiration of the affected knee joint. These times correspond to the beginning and end of each treatment 
phase. Synovial fluid was aspirated under local anaesthesia. A 21 gauge needle and a $10 \mathrm{ml}$ Terumo syringe were used. The aspirate volume was determined from calibration marks on the syringe. A single operator who did not have access to the preceding aspirate volumes carried out all joint aspirations. Joints were aspirated as near as possible to dryness.

\section{KERATAN SULPHATE ASSAY}

The assay for keratan sulphate was adapted from the assay for sulphated glycosaminoglycans by predigesting samples with chondroitin $\mathrm{ABC}$ lyase. This assay is described in detail elsewhere. $^{12-14}$ Aliquots of synovial fluid $(40 \mu \mathrm{l})$ were added to $140 \mu \mathrm{l}$ of $0.02 \mathrm{~mol} / \mathrm{l}$ TRIS-HCl (pH 8.0) and thoroughly mixed to ensure dispersion of the synovial fluid into the buffer. To this diluted synovial fluid was added $20 \mu \mathrm{l}$ of $0.02 \mathrm{~mol} / \mathrm{l}$ TRIS-HCl buffer ( $\mathrm{pH} \mathrm{8.0)}$ containing $5 \mathrm{U} / \mathrm{ml}$ chondroitin $\mathrm{ABC}$ lyase. The tubes were then gently mixed and incubated for four hours at $37^{\circ} \mathrm{C}$.

Preliminary studies showed that when synovial fluids are digested under these conditions keratan sulphate is the only remaining sulphated glycosaminoglycan. After digestion with chondroitin $\mathrm{ABC}$ lyase $100 \mu \mathrm{l}$ aliquots of the digest were transferred to fresh tubes and mixed with an equal volume of $0.02 \mathrm{~mol} / 1$ TRIS-HCl buffer (pH 7.00) containing 0.004 $\mathrm{mol} / \mathrm{l} N$-acetyl cysteine and $0 \cdot 13$ units of papain. All samples were then mixed and incubated for two hours at $65^{\circ} \mathrm{C}$. On completion of this digestion the papain was inactivated and the ionic strength of the solution adjusted as described previously. Aliquots $(40 \mu \mathrm{l})$ of the final digest were then transferred to the wells of a microtitre plate and mixed with $250 \mu \mathrm{l}$ of dimethylmethylene blue dye. The dimethylmethylene blue reagent was prepared by adding $3.04 \mathrm{~g}$ glycine, $2.37 \mathrm{~g} \mathrm{NaCl}$, and $16 \mathrm{mg} 1,9-$ dimethylmethylene blue to 1 litre of doubly distilled water. The $\mathrm{pH}$ was adjusted to 3.0 with $\mathrm{HCl}$ and the reagent was stored in a light shielded bottle. Absorbances were read at $540 \mathrm{~nm}$. The assay was calibrated with keratan sulphate from bovine cornea. Control samples of purified chondroitin sulphate and keratan sulphate diluted in phosphate buffered physiological saline containing bovine serum albumin $(40 \mathrm{mg} / \mathrm{l})$ were processed in the same way as biological samples to monitor the efficacy of the chondroitin sulphate elimination and to ensure that the keratan sulphate concentrations were not affected by the assay procedure. Amounts of keratan sulphate ranging from 0.5 to $4.0 \mu \mathrm{g}$ were added to $100 \mu \mathrm{l}$ aliquots of inflammatory and non-inflammatory synovial fluid to investigate the extent to which keratan sulphate is recovered in the assay. More than $\mathbf{9 8 \%}$ recovery was noted in both types of synovial fluid.

\section{STATISTICAL METHODS}

The effect of piroxicam on clinical and laboratory variables was measured by comparing the scores at the end of the piroxicam treatment phase (week 8) with the scores at the end of the first placebo phase (week 4). A paired $t$ test (or signed rank sum test for paracetamol consumption) was used to test the significance of mean differences observed. Similarly the effect of stopping treatment was determined by comparing the week 12 scores with those at week 8 .

\section{Results}

Twenty one patients ( 13 women, eight men) were enrolled in the study and 19 (11 women, eight men) completed the treatment course. One patient withdrew owing to oedema and another owing to purpura. These reactions resolved completely when treatment with piroxicam was stopped. The median age of the 19 patients completing the study was 70 years (range 52-81 years).

Figure 1 shows the results for pain score, range of joint movement, and functional index. The mean change for these variables is shown in the table. Treatment with piroxicam was accompanied by a statistically significant decrease in pain score $(\mathrm{p}<0.05)$ and a significant improvement in the range of joint movement $(p<0.01)$ and functional index $(p<0.02)$. Lower paracetamol consumption was also observed during treatment with piroxicam $(\mathrm{p}<0.05$, data not shown). Cross over to the placebo at the end of the period of treatment with piroxicam was accompanied by a significant deterioration in pain score $(p<0.002)$ and functional index $(p<0.01)$ after a further four weeks.

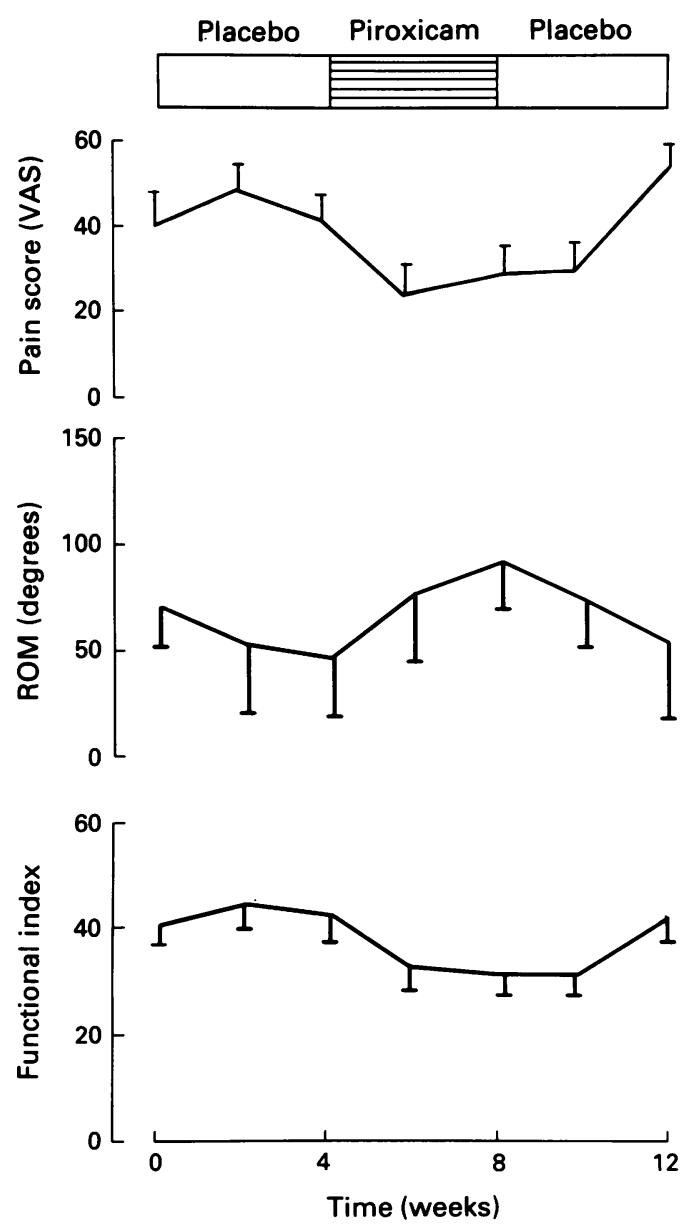

Figure 1 Pain score, range of joint movement (ROM), and functional index before, during, and after treatment with piroxicam. Results are mean (SEM) values. 
A trend towards a reduced range of movement was also observed during the the second placebo phase. Interestingly, deterioration in the pain score and functional index was not apparent until four weeks after piroxicam was withdrawn (see fig 1). These sustained effects may be due to the long half life of the drug.

Figure 2 shows the mean volume of synovial fluid aspirated at each time point during the study, together with the keratan sulphate concentrations and the total amount of keratan

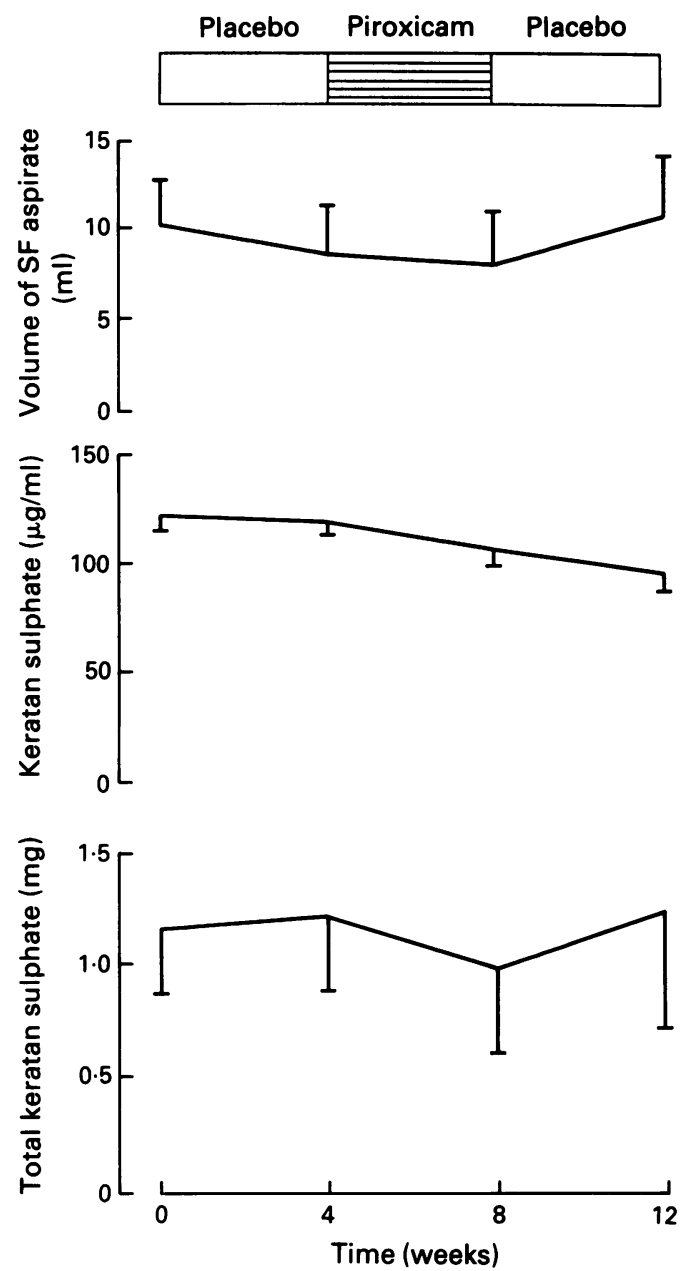

Figure 2 Volume of synovial fluid $(S F)$ aspirate, concentration of keratan sulphate in the synovial fluid, and total amounts of keratan sulphate in the joint aspirate before, during, and after treatment with piroxicam. Results are mean (SEM) values. sulphate in the joint cavity (product of volume and keratan sulphate concentrations) at these times. No significant changes in aspirate volume were observed during the study. A slight decrease was noted during the first placebo phase as well as during treatment with piroxicam, and an increase was observed during the second placebo phase. Treatment with piroxicam was accompanied by a quantitatively small, but statistically significant, decrease in the keratan sulphate concentration $(p<0.02)$. A further but not statistically significant decline in keratan sulphate concentration was also observed during the second placebo phase. In three patients who did not resume treatment with NSAIDs at the completion of the study and in whom aspirates were available four weeks later, the keratan sulphate concentration was found to increase from $106(22) \mu \mathrm{g} / \mathrm{ml}$ after receiving piroxicam for four weeks to 121 (10) $\mu \mathrm{g} / \mathrm{ml}$ eight weeks after stopping treatment with the drug. Taken together these observations indicate that treatment with piroxicam lowers the keratan sulphate concentrations in synovial fluid from patients with osteoarthritis and suggest that this reduction continues after stopping treatment with the drug for up to eight weeks. The total amount of keratan sulphate in the joint cavity also declined significantly during treatment with piroxicam $(\mathrm{p}<0.05$; fig 2 ). A moderate increase in the total keratan sulphate concentration was observed during the second placebo phase, but this was not significant. It should be noted that aspirate volumes, keratan sulphate concentrations, and total keratan sulphate values were only available in subsets of the total group of patients (as shown in the table) due to some unsuccessful aspirations, the occasional retrieval of indeterminate volumes occupying only the dead space in the syringe, and contamination of some samples with blood.

\section{Discussion}

These results confirm the clinical efficacy of piroxicam in osteoarthritis and show that it does affect cartilage proteoglycan metabolism. ${ }^{15}$ The proteoglycans in articular cartilage are composed of a core protein to which sulphated glycosaminoglycans are attached. ${ }^{16}$ The most abundant type of cartilage proteoglycans contain

Effects of treatment with piroxicam

\begin{tabular}{|c|c|c|c|c|c|c|}
\hline \multirow[t]{2}{*}{ Variable } & \multicolumn{3}{|c|}{ Effect of starting treatment } & \multicolumn{3}{|c|}{ Effect of stopping treatment } \\
\hline & $\begin{array}{l}\text { Mean change } \\
(95 \% \text { CI })^{*}\end{array}$ & $\begin{array}{l}\text { Number of } \\
\text { patients }\end{array}$ & p Value & $\begin{array}{l}\text { Mean change } \\
\left(95 \%(I)^{*}\right.\end{array}$ & $\begin{array}{l}\text { Number of } \\
\text { patients }\end{array}$ & p Value \\
\hline Pain score ( $\mathrm{mm}$ on VAS) $\dagger$ & $\begin{array}{l}-13 \cdot 4 \\
(-26 \cdot 1 \text { to }-0 \cdot 7)\end{array}$ & 19 & $<0.05$ & $\begin{array}{l}22 \cdot 5 \\
(9 \cdot 7 \text { to } 35 \cdot 4)\end{array}$ & 19 & $<0.002$ \\
\hline $\begin{array}{l}\text { Range of movement } \\
\text { (degrees) }\end{array}$ & $\begin{array}{l}6 \cdot 0 \\
(2 \cdot 0 \text { to } 10 \cdot 0)\end{array}$ & 19 & $<0.01$ & $\begin{array}{l}-4 \cdot 9 \\
(-12 \cdot 6 \text { to } 2 \cdot 8)\end{array}$ & 19 & NS \\
\hline $\begin{array}{l}\text { Functional index } \\
\text { (Bellamy Index) }\end{array}$ & $\begin{array}{l}-12 \cdot 6 \\
(-21 \cdot 9 \text { to }-3 \cdot 3) \\
-1.2\end{array}$ & 19 & $<0.02$ & $\begin{array}{l}13 \cdot 7 \\
(5 \cdot 3 \text { to } 22 \cdot 2) \\
1.5\end{array}$ & 19 & $<0.01$ \\
\hline Volume of aspirate $(\mathrm{ml})$ & $(-3 \cdot 0$ to $0 \cdot 6)$ & 16 & NS & $(-1 \cdot 6$ to $4 \cdot 6)$ & 17 & No \\
\hline sulphate $(\mathrm{mg})$ & $\begin{array}{l}-0.3 \\
(-0.5 \text { to } 0)\end{array}$ & 15 & $<0.05$ & $\begin{array}{l}0.2 \\
(-0.1 \text { to } 0.6)\end{array}$ & 12 & NS \\
\hline $\begin{array}{l}\text { Concentration of keratan } \\
\text { sulphate }(\mu \mathrm{g} / \mathrm{ml})\end{array}$ & $\begin{array}{l}-14 \\
(-24 \text { to }-4)\end{array}$ & 14 & $<0.02$ & $\begin{array}{l}-1 \\
(-11 \text { to } 13)\end{array}$ & 13 & NS \\
\hline
\end{tabular}

$\mathrm{CI}=$ confidence interval.

+VAS $=$ visual analogue scale. 
two types of glycosaminoglycans: chondroitin sulphate and keratan sulphate. ${ }^{17}$ Whereas most of the tissues in joints produce proteoglycans which contain chondroitin sulphate, those containing keratan sulphate are restricted to articular cartilage. ${ }^{18-20}$ In view of this specificity keratan sulphate can be used indirectly to measure cartilage proteoglycans in joint fluid.

In this study a significant reduction in the concentration and total amount of keratan sulphate in synovial fluid was observed during treatment with piroxicam. There are several possible explanations for these findings. They include: dilution effects; decreased proteoglycan synthesis; enhanced proteoglycan clearance; and decreased proteoglycan catabolism.

\section{DILUTION EFFECTS}

It is very unlikely that dilution effects are responsible for the reduction in keratan sulphate concentration. We and other workers have previously shown that the concentrations of proteoglycans and keratan sulphate in synovial fluid are not related to effusion volume as would be expected if dilution was an important factor. ${ }^{14} 21$ Furthermore, in this study the effusions did not increase in size during treatment with piroxicam; on the contrary, there was a slight decrease.

\section{REDUCED PROTEOGLYCAN SYNTHESIS}

Proteoglycans are thought to be released into synovial fluid in a degraded form, but it is possible that some of the molecules in the joint fluid represent recently synthesised molecules which have not become incorporated into the matrix and have diffused out of the tissue intact. Failure to incorporate the molecules could occur, for example, if these proteoglycans did not have a functional hyaluronic acid binding region or could not bind to hyaluronic acid due to a lack of available receptor sites. In previous studies we have found that the proteoglycan fragments in normal and osteoarthritic synovial fluid do not bind to hyaluronic acid. ${ }^{22}$ As the capacity to bind may have been lost as a result of degradation after release from the cartilage, however, the presence of some newly synthesised proteoglycans in the joint fluid cannot be discounted. It is worth noting that piroxicam has been found to have either no effect or to increase proteoglycan synthesis in human cartilage explants. ${ }^{83}$ Furthermore, piroxicam has no effect on proteoglycan synthesis in cultured pig cartilage. ${ }^{23}$

On the basis of these observations it seems unlikely that the reduced concentrations and total amount of keratan sulphate in osteoarthritic joint fluid are due to effects of piroxicam on proteoglycan synthesis.

\section{ENHANCED PROTEOGLYCAN CLEARANCE}

Most of the degraded proteoglycans in joint fluid are too large to be cleared by the circulation and are believed to leave the joint through lymphatic channels. ${ }^{2+}$ Whether piroxicam affects proteoglycan clearance is unknown, but a substantial effect is unlikely as proteoglycan clearance is a function of volume, which did not change appreciably, and the removal rate constant for proteoglycans, which has been found to be independent of inflammatory activity. ${ }^{25} 26$

\section{DECREASED PROTEOGLYCAN CATABOLISM}

The decline in synovial fluid keratan sulphate also raises the possibility of reduced release of proteoglycans from the cartilage matrix as a consequence of decreased catabolism. This is supported by the findings of Verbruggen et al who reported an inhibitory effect of piroxicam on the release of pulse chase radiolabelled proteoglycan in human cartilage explants. ${ }^{8}$ In view of the widespread use of piroxicam and other NSAIDs in the treatment of arthritis it will be important to determine whether effects on cartilage proteoglycan metabolism persist with continued treatment and, most importantly, whether treatment with piroxicam or related drugs slows the rate of radiologically apparent cartilage resorption in patients with this disease.

The authors thank Ms S Dalgarno for secretarial assistance, the Roval Perth Hospital Research Foundation for the provision of laboratory facilities, and the Western Australian Arthritis and Rheumatism Foundation and Pfizer Pty Ltd for generous financial support.

1 Peyron J. The epidemiology of osteoarthritis. In: Moskowitz R W, Howell D S, Goldberg V M and Mankin H J, eds. Osteoarthritis diagnosis and management. Philadelphia: Osteoarthritts diagnosis

2 Palmoski M J, Brandt K D. Effect of salicylate on proteoglycan metabolism in normal canine articular cartilage in vitro. Arthritis Rheum 1979; 22: 746-54.

3 Palmoski M J, Brandt K D. Effects of some nonsteroidal antiinflammatory drugs on proteoglycan metabolism and organization in canine articular cartilage. Arthritis Rheum 1980; 23: 1010-20.

4 Palmoski M J, Colyer R, Brandt K D. Marked suppression by salicylate of the augmented proteoglycan synthesis in

5 Palmoski M J, Brandt K D. In vivo effect of apsirin on canine osteoarthritic cartilage. Arthritis Rheum 1983;26: 994-1001. 6 Palmoski M J, Brandt K D. Aspirin aggravates the degeneration of canine joint cartilage caused by immobilization. eration of canine joint cartilage caused

7 Maier R, Wilhelmi G. Preclinical investigations of drug effects in models of osteoarthrosis. In: Munthe E, Bielle A, eds. Effects of drugs on osteoarthrosis. Berne: Hans Huber, 1984: 90-9.

8 Verbruggen G, Veys E M, Malfait A-M, et al. Proteoglycan metabolism in tissue cultured human articular cartilage. Influence of piroxicam. 7 Rheumatol 1989; 16: 355-62

9 Altman R, Asch E, Bloch D, et al. Development of criteria for the classification and reporting of osteoarthritis. Arthritis Rheum 1986; 29: 1039-49.

10 Norkin C C, White D J, Joyce D. Measurement of joint range: a guide to goniometry. Philadelphia: Davis, $1985^{\circ}$

11 Bellamy N, Buchanan W W. A preliminary evaluation of the dimensionality and clinical importance of pain and disability in osteoarthritis of the hip and knee. Clin Rheumatol 1985 5: $231-41$

12 Farndale R W, Buttle D J, Barret A J. Improved quantitation and discrimination of sulphated glycosaminoglycans bv use of dimethylmethylene blue. Biochim Biophvs Acta 1986; 883: 173-7.

13 Carroll G J. Spectrophotometric measurement of proteoglycans in osteoarthritic synovial fluid. Ann Rheum Dis 1987; 46: 375-9.

14 Carroll G J, McCappin S, Bell M C, Schwar\%er A, Breidahl P. Comparison of keratan sulphate concentrations and the size distribution of proteoglycans in the svnovial fluid of patients with osteoarthritis and pyrophosphate arthropathy. patients with osteoarthritis and pyr
Rheumatol Int 1991; 11: 63-8.

15 Zizic T M, Sutton J D, Stevens M B. Piroxicam and osteoarthritis: a controlled study. Roval Society of Medicine International Congress Symposium Series 1978; $1: 71-81$

16 Muir I H. In: Sokoloff L, ed. The joints and symozial fluid. New York: Academic Press, 1980: 27-94

17 Seno N, Meyer K, Anderson B, Hoffman P. Variations in keratosulphates., f Biol Chem 1965; 240: 1005-10. 
18 Hamerman D, Smith C, Keiser H D, Craig R. Glycosaminoglycans produced by human synovial cell cultures. Coll Relat Res 1982; 2: 313-29.

19 Bayliss M T, Venn M, Maroudas A, Ali Y. Structure of proteoglycans from different layers of human articular cartilage. Biochem $\mathcal{F}$ 1983; 209: 387-400.

20 Habuchi H, Yamagata T, Iwata $H$, Suzuki S. The occurrence of a wide variety of dermatan sulphate-chondroitin sulphate copolymers in fibrous cartilage. 7 Biol Chem 1973; 248: copolymers

21 Saxne T, Heinegărd D, Wollheim F A. Therapeutic effects on cartilage metabolism in arthritis as measured by release of proteoglycan structures into the synovial fluid. $A n n$ Rheum Dis 1986, 30: 972-9.

22 Carroll G J, McCappin S, Bell M C. Measurement and characterisation of proteoglycans in normal and osteoarthritic synovial fluid. In: Methods used in research on cartilaginous tissues. Abstracts of Bat Sheva Seminar, 1989. 23 Verbruggen G, Veys E M, Malfait A M, et al. Proteoglycan metabolism in isolated chondrocytes from human cartilage and in short term tissue-cultured human articular cartilage. Clin Exp Rheumatol 1989; 7: 13-7.

24 Simkin P A, Nilson K L. Trans-synovial exchange of large and small molecules. Clin Rheum Dis 1981; 7: 99-129.

25 Wallis W J, Simkin P A, Nelp W B, Foster D M. Intraarticular volume and clearance in human synovial effusions. articular volume and clearance in
Arthritis Rheum 1985; 28: 441-9.

26 Page-Thomas D P, Bard D, King B, Dingle J T. Clearance of proteoglycan from joint cavities. Ann Rheum Dis 1987; 46: 934-7. 